\title{
Effect of lactoferrin feeding on the host antifungal response in guinea-pigs infected or immunised with Trichophyton mentagrophytes
}

\author{
HIROYUKI WAKABAYASHI*†, NATSUKO TAKAKURA*, KOJI YAMAUCHI*, \\ SUSUMU TERAGUCHI*, KATSUHISA UCHIDA $\dagger$, HIDEYO YAMAGUCHI $\dagger$ and \\ YOSHITAKA TAMURA*
}

* Nutritional Science Laboratory, Morinaga Milk Industry Co. Ltd, Zama, Kanagawa 228-8583 and †Teikyo University Institute of Medical Mycology, Hachioji, Tokyo 192-0395, Japan

\begin{abstract}
Earlier studies revealed that oral administration of lactoferrin (LF), a multi-functional milk protein, facilitated curing of dermatophytosis in guinea-pigs and man by an unknown mechanism. The present study aimed to assess the effect of feeding bovine LF on the host antifungal defence systems in guinea-pigs infected or immunised with Trichophyton mentagrophytes, a dermatophytosis-causing fungus. The unbound ironbinding capacity (UIBC) of the plasma of individual animals varied, and plasma with higher UIBC inhibited growth of T. mentagrophytes in vitro. However, LF administration did not enhance plasma UIBC or the anti-T. mentagrophytes activity of plasma in infected or uninfected animals. Phagocytic activity and reactive oxygen (RO) production of blood neutrophil polymorphonuclear leucocytes (PMNLs) were estimated by flow cytometry. LF administration caused no significant effects on phagocytic activity or RO production of neutrophil PMNLs in infected or uninfected animals. The functions of mononuclear cells (MNC) from the spleen were investigated in guinea-pigs immunised with heat-killed T. mentagrophytes conidia. The MNC were cultured with concanavalin A or inactivated $T$. mentagrophytes. In the bromo-deoxyuridine incorporation assay, the stimulation index was higher for MNC derived from LF-treated animals than for those from control animals. The culture supernates of MNC enhanced the ability of macrophages to kill T. mentagrophytes conidia. Furthermore, stronger augmentation was observed with the culture supernate from LF-treated animals than with that from control animals. In conclusion, LF feeding may potentiate the host antifungal defence systems by modulating MNC function rather than plasma antifungal activity or peripheral blood neutrophil PMNL activity.
\end{abstract}

\section{Introduction}

Lactoferrin (LF) is a transferrin-family iron-binding glycoprotein present in milk and other exocrine secretions as well as in neutrophil polymorphonuclear leucocyte (PMNL) granules. It is thought to play an important role in host defence because it exhibits a variety of biological activities, including antimicrobial activity and immunomodulatory effects, as shown by in-vitro studies $[1,2]$. It is increasingly appreciated that oral administration of LF or its fragment peptides

Received 15 April 2002; accepted 16 May 2002.

Corresponding author: Dr H. Wakabayashi (e-mail: h_wakaby @morinagamilk.co.jp). improves the survival rate and enhances elimination of pathogens from the body of animals or human patients infected with bacteria, fungi, protozoa or viruses [3-7]. Recent studies showed that feeding bovine LF enhances the elimination of pathogens and the rate of symptomatic cure in guinea-pigs and man with dermatophytosis, a very common fungal infection on the skin $[8,9]$. LF exhibits in-vitro growth-inhibitory activity against the dermatophytes Trichophyton mentagrophytes and T. rubrum, causative fungi of dermatophytosis [8]. However, the mechanism by which LF provides protection against dermatophytosis in vivo remains unknown.

The host antifungal response against dermatophytosis is considered to involve the following mechanisms. First, 
it has been demonstrated that the anti-dermatophyte activity of serum is due to iron-unsaturated transferrin, which is expressed as serum unbound iron-binding capacity (UIBC) [10,11]. Likewise, iron-unsaturated LF may have a role in the inhibition of dermatophytes [8]. Second, phagocytes (including neutrophil PMNLs and macrophages) may be involved in the eradication of dermatophytes, because dense infiltration of neutrophil PMNLs is observed in infected areas of the skin of man and animals with dermatophytosis $[12,13]$, and neutrophil PMNLs and macrophages exhibit killing activity against Trichophyton spp. in vitro [14]. Third, the development of cell-mediated immunity correlated with delayed hypersensitivity and an inflammatory response is associated with clinical cure, whereas the lack of, or a defective, cell-mediated immunity predisposes the host to chronic or recurrent dermatophyte infection $[15,16]$. In response to stimulation by Trichophyton antigens, interferon (IFN)- $\gamma$, interleukin (IL)-2 and granulocyte-macrophage colony-stimulating factor (GM-CSF) are produced by peripheral blood MNC obtained from patients with acute dermatophytosis, whereas markedly lower levels of IFN- $\gamma$ production are found in the case of chronically infected patients [17-20]. These cytokines released from MNC may participate in the activation of phagocytic cells in the infected site.

To evaluate the effect of feeding bovine LF on the host antifungal response, the following activities were tested in guinea-pigs infected or immunised with T. mentagrophytes. In infected or uninfected animals, plasma UIBC, plasma anti-T. mentagrophytes activity and blood neutrophil activities - phagocytic activity and reactive oxygen $(\mathrm{RO})$ production - were compared in the LF-treatment group and non-treatment group. In immunised or non-immunised animals, the proliferative response and the effector activity of splenic MNC were examined. Culture supernates of MNC were assessed for their capacity to augment the ability of macrophages to kill T. mentagrophytes conidia.

\section{Materials and methods}

\section{T. mentagrophytes}

T. mentagrophytes TIMM2789 was obtained from the culture collection of Teikyo University Institute of Medical Mycology (Tokyo, Japan) and maintained on Sabouraud glucose agar (peptone $1 \%$, glucose $2 \%$, agar $1.5 \%)$ slants. A conidial suspension was prepared in physiological saline containing Tween $80 \quad 0.05 \%$ from cultures grown on modified Sabouraud glucose agar (peptone $0.2 \%$, glucose $0.1 \%, \mathrm{KH}_{2} \mathrm{PO}_{4} 0.1 \%, \mathrm{MgSO}_{4}$ $0.1 \%$, agar $2 \%$ ) slants at $27^{\circ} \mathrm{C}$ for 2 weeks. The suspension was filtered through sterilised gauze to remove hyphal fragments and agar debris, and adjusted to a cell concentration of $2 \times 10^{7}$ conidia $/ \mathrm{ml}$ for inoculation of animals or $10^{7}$ conidia $/ \mathrm{ml}$ for tests of T. mentagrophytes-killing by macrophages or $10^{4}$ conidia/ml for plasma antifungal tests. For use in immunisation, the suspension was resuspended in distilled water at $10^{7}$ conidia $/ \mathrm{ml}$ and autoclaved at $121^{\circ} \mathrm{C}$ for $15 \mathrm{~min}$.

\section{Guinea-pigs and oral administration of $L F$}

Female Hartley SPF guinea-pigs (7-9-week-old) (Japan SLC, Shizuoka, Japan) were used for all animal experiments. Animals were given bovine LF (Morinaga Milk Industry Co., Tokyo, Japan) solution (250 $\mathrm{mg} / \mathrm{ml}$ ), orally, twice a day at a daily LF dose of $2.5 \mathrm{~g} / \mathrm{kg}$ body weight by gavage. The untreated control group received the same volume of water or did not receive any test solution. The animal study protocol was approved by the Morinaga Milk Industry Animal Research Committee, and the guinea-pigs were maintained according to the guidelines for the care and use of laboratory animals of Morinaga Milk Industry.

\section{Dermatophytosis model}

Experiments with dermatophytosis on the back (tinea corporis) of guinea-pigs were performed as described previously [8]. Briefly, each animal's back was inoculated with $50 \mu \mathrm{l}$ of $T$. mentagrophytes conidial suspension. Three weeks after infection, animals were killed and heparinised blood was collected by cardiac puncture. LF was administered from 3 days after infection to 1 day before the sampling day (for 2.5 weeks) or from 7 days before infection to 1 day before the sampling day (for 4 weeks).

\section{Immunisation and isolation of $M N C$}

Equal volumes of the heat-killed T. mentagrophytes cell preparation and complete Freund's adjuvant were mixed and emulsified, and $200 \mu \mathrm{l}$ of the solution were injected subcutaneously into a footpad of each animal. Thereafter, LF was administered for 7 days. At 7 days after immunisation, the spleen was removed, minced in Hanks's Balanced Salts Solution (HBSS), and passed through a Falcon cell strainer (Becton Dickinson Labware, Franklin Lakes, USA). After erythrocytes were removed by treating the cell suspensions with ACK lysing buffer [21], the cell suspensions were layered on Ficoll-Paque Plus (Pharmacia Biotech, Tokyo, Japan) and centrifuged at $550 \mathrm{~g}$ for $30 \mathrm{~min}$ at room temperature. The MNC layer was collected, washed with HBSS and suspended in RPMI 1640 medium supplemented with $20 \mathrm{mM}$ HEPES, $16 \mathrm{mM}$ $\mathrm{NaHCO}_{3}$, penicillin $100 \mathrm{mg} / \mathrm{L}$, kanamycin $100 \mathrm{mg} / \mathrm{L}$ and heat-inactivated FCS 5\% (complete medium).

\section{UIBC and anti-T. mentagrophytes activity}

Plasma UIBC of animals was estimated by the UIBCTest Wako (Wako Junyaku Kogyo, Osaka, Japan); $50 \mu \mathrm{l}$ of filter-sterilised plasma, $20 \mu \mathrm{l}$ of $T$. mentagrophytes conidial suspension, and $130 \mu \mathrm{l}$ of RPMI 1640 
supplemented with 0.165 M MOPS, a medium recommended by the NCCLS for susceptibility testing of filamentous fungi [22], were added to each well of a 96-well flat-bottomed microtitration plate. The inoculated plates were incubated at $27^{\circ} \mathrm{C}$ for 7 days. The fungal growth was measured spectrophotometrically at $\mathrm{OD}_{630}$.

\section{Phagocytic activity and $\mathrm{RO}$ production of neutrophils}

To measure the phagocytic activity, $100 \mu \mathrm{l}$ of heparinised blood and $100 \mu \mathrm{l}$ of FITC-labelled beads (Polysciences, Warrington, USA) at $5 \times 10^{7} / \mathrm{ml}$ were mixed and incubated for $15 \mathrm{~min}$ at $37^{\circ} \mathrm{C}$. To measure the RO production, heparinised blood was incubated at room temperature for $30 \mathrm{~min}$ after mixing with an equal volume of dextran (Nakarai Tesque, Kyoto, Japan) $5 \%$ in phosphate-buffered saline (PBS), and the buffy coat was resuspended in PBS. Then $20 \mu \mathrm{l}$ of the separated blood and $130 \mu \mathrm{l}$ of $5 \mu \mathrm{M} 2^{\prime}, 7^{\prime}-$ dichlorofluorescein diacetate (Kodak, Rochester, USA) in PBS were mixed and incubated for $15 \mathrm{~min}$ at $37^{\circ} \mathrm{C}$; $30 \mu \mathrm{l}$ of $20 \mathrm{mM}$ EDTA and $20 \mu \mathrm{l}$ of phorbol myristate acetate (PMA) $25 \mu \mathrm{g} / \mathrm{ml}$ were added to each tube and incubated for $15 \mathrm{~min}$ at $37^{\circ} \mathrm{C}$. Finally, red blood cells were lysed with Lysing Solution (Becton Dickinson, San Jose, USA). The cells were resuspended in PBS and the fluorescence in the neutrophil PMNLs was analysed by flow cytometry (EPICS, Coulter, Hialeah, USA).

\section{Proliferation of $M N C$}

MNC at $5 \times 10^{5}$ cells $/ \mathrm{ml}$ were incubated in complete medium at $37^{\circ} \mathrm{C}$ for 3 days in an humidified atmosphere of $\mathrm{CO}_{2} 5 \%$ in air $95 \%$ with stimulation by concanavalin A (ConA; Sigma) $10 \mu \mathrm{g} / \mathrm{ml}$ or a $10 \%$ suspension of heat-killed T. mentagrophytes cells (final concentration $10^{6}$ conidia $/ \mathrm{ml}$ ). The cells were pulselabelled with bromo-deoxyuridine (BrdU) solution (Cell Proliferation ELISA System, Amersham Life Science, Tokyo, Japan) during the last $2 \mathrm{~h}$ of incubation. Then BrdU incorporated into the cells was quantified with an anti-BrdU monoclonal antibody (MAb) according to the method recommended by the manufacturer. The stimulation index was calculated by dividing the BrdU incorporation of cells with stimulation by the BrdU incorporation of cells without stimulation.

\section{T. mentagrophytes-killing activity of macrophages}

$\mathrm{MNC}$ at $5 \times 10^{6}$ cells $/ \mathrm{ml}$ were stimulated by incubation with ConA $10 \mu \mathrm{g} / \mathrm{ml}$ or a $10 \%$ suspension of heatkilled T. mentagrophytes cells. After incubation for 2 days, the culture supernate was collected. The macrophage killing activity was assayed according to the method of Calderon and Hay [14]. Peritoneal cells containing resident macrophages were collected after injection of PBS. Various numbers of the cells suspended in complete medium were added to the wells of a 96-well flat-bottomed plate and incubated for $2 \mathrm{~h}$. After removal of non-adhesive cells, T. mentagrophytes conidia at an E/T ratio of $0 / 1$ to $25 / 1$ and defined amounts of MNC culture supernate or recombinant rat IFN- $\gamma$ (Genzyme, Cambridge, USA) were added to the wells and incubated in complete medium at $37^{\circ} \mathrm{C}$ for $19 \mathrm{~h}$. After vigorous shaking of the plates, $30 \mu \mathrm{l}$ of the cell suspension from each well were transferred to a petri dish and mixed with $20 \mathrm{ml}$ of Sabouraud glucose agar warmed to $45^{\circ} \mathrm{C}$. The agar plates were incubated at $27^{\circ} \mathrm{C}$ for $2-3$ days and the number of fungal colonies formed was counted. The percentage T. mentagrophytes-killing was calculated as follows: killing $(\%)=100-($ test $\mathrm{cfu} /$ control cfu $)$ $\times 100$.

\section{Results}

\section{UIBC and antifungal activity of plasma}

Normal guinea-pigs were administered water for 2 weeks or LF for 1 or 2 weeks. One day after the administration period, blood plasma was collected for measurement of the UIBC and anti-T. mentagrophytes activity (Fig. 1a). The individual plasma samples had UIBC ranging from 0.6 to $1.5 \mu \mathrm{g} / \mathrm{ml}$. Whereas the plasma showing higher UIBC inhibited growth of $T$. mentagrophytes, the plasma showing lower UIBC promoted the growth compared with medium only. However, no difference of plasma UIBC or the effect on $T$. mentagrophytes growth was observed between control animals and LF-treated animals. Guinea-pigs were infected with $T$. mentagrophytes and administered nothing or LF for 2.5 or 4 weeks. Three weeks after infection, plasma UIBC and anti-T. mentagrophytes activity were measured (Fig. 1b). Plasma collected from infected animals exhibited UIBC ranging from 0.8 to $2.0 \mu \mathrm{g} / \mathrm{ml}$. No obvious difference of plasma UIBC and the effect on Trichophyton growth was seen between control animals and LF-treated animals. The plasma from two LF-treated animals promoted rather than inhibited growth of T. mentagrophytes, whereas none of the plasma from control animals showed such an effect.

\section{Neutrophil PMNL activities}

The phagocytic activity and RO production of neutrophil PMNLs was measured in control and LF-treated animals. The phagocytic activity of neutrophil PMNLs from control animals was lower in infected animals than in uninfected animals (Fig. 2a). LF administration tended to enhance the phagocytic activity in infected animals, but the effect was not significant $(\mathrm{p}=0.128$ for $L F 2.5 \mathrm{w}$ and $\mathrm{p}=0.061$ for $\mathrm{LF} 4 \mathrm{w}$ ). RO production of neutrophil PMNLs was higher in infected animals than in uninfected animals (Fig. 2b). However, LF 


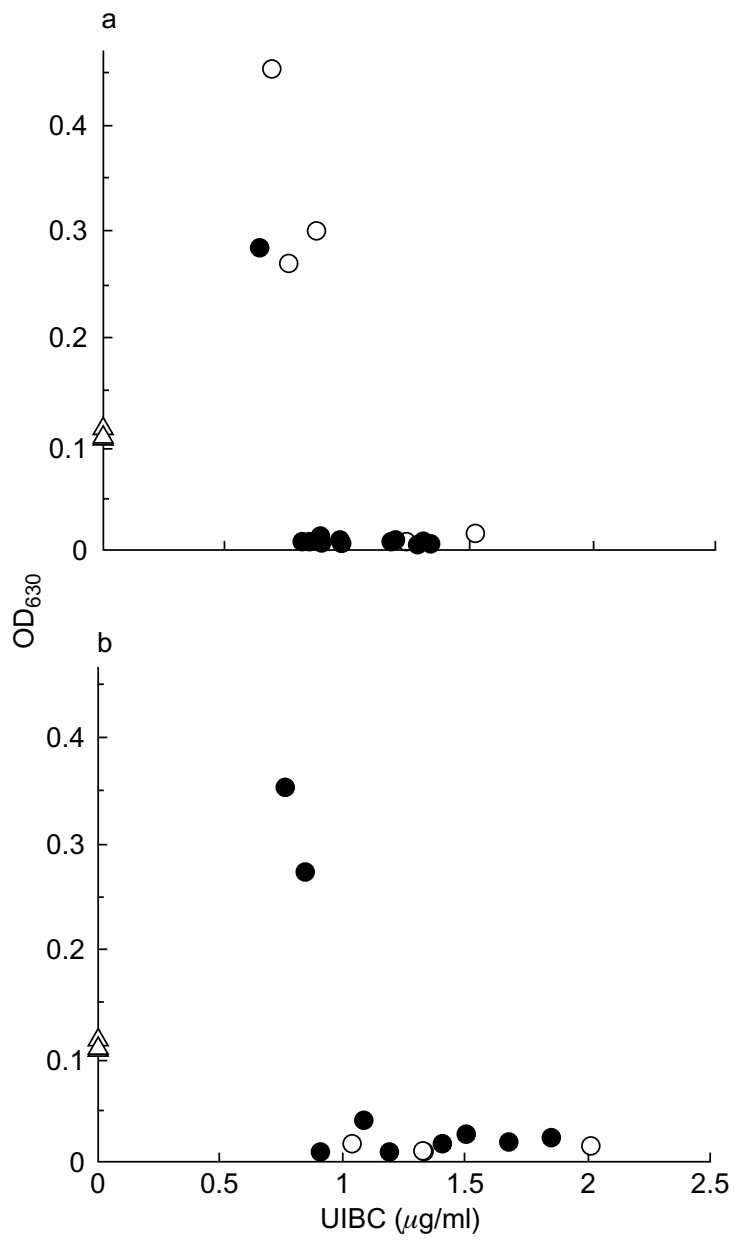

Fig. 1. Plasma UIBC and the effect on growth of T. mentagrophytes. Normal guinea-pigs were given water $(\mathrm{n}=6)$ or LF $(\mathrm{n}=12)$. T. mentagrophytes-infected guinea-pigs were given nothing $(n=6)$ or LF $(n=8)$. One day after the administration period, the plasma of each individual guinea-pig was diluted to $25 \%$ concentration in RPMI 1640 medium and incubated with $T$. mentagrophytes conidia for 7 days, and the fungal growth was measured spectrophotometrically. UIBC and the effect on T. mentagrophytes growth of the plasma from each individual normal animal (a) and infected animal (b) were plotted for the control $(\mathrm{O})$ and LF-treatment $(O)$ groups. $\triangle$, results obtained with medium alone.

administration did not significantly change the RO production of neutrophil PMNLs.

\section{Proliferation of $M N C$}

Guinea-pigs were immunised with heat-killed $T$. mentagrophytes cells or were non-immunised, and LF was administered for 1 week. One week after immunisation, the proliferative response of splenic MNC to stimulation by ConA or heat-killed $T$. mentagrophytes during a 3-day incubation period was examined. The stimulation index determined by BrdU incorporation is shown in Fig. 3. In both nonimmunised and immunised animals, LF administration significantly enhanced the stimulation index of MNC stimulated with ConA or heat-killed T. mentagrophytes. The stimulation index of MNC from LF-treated
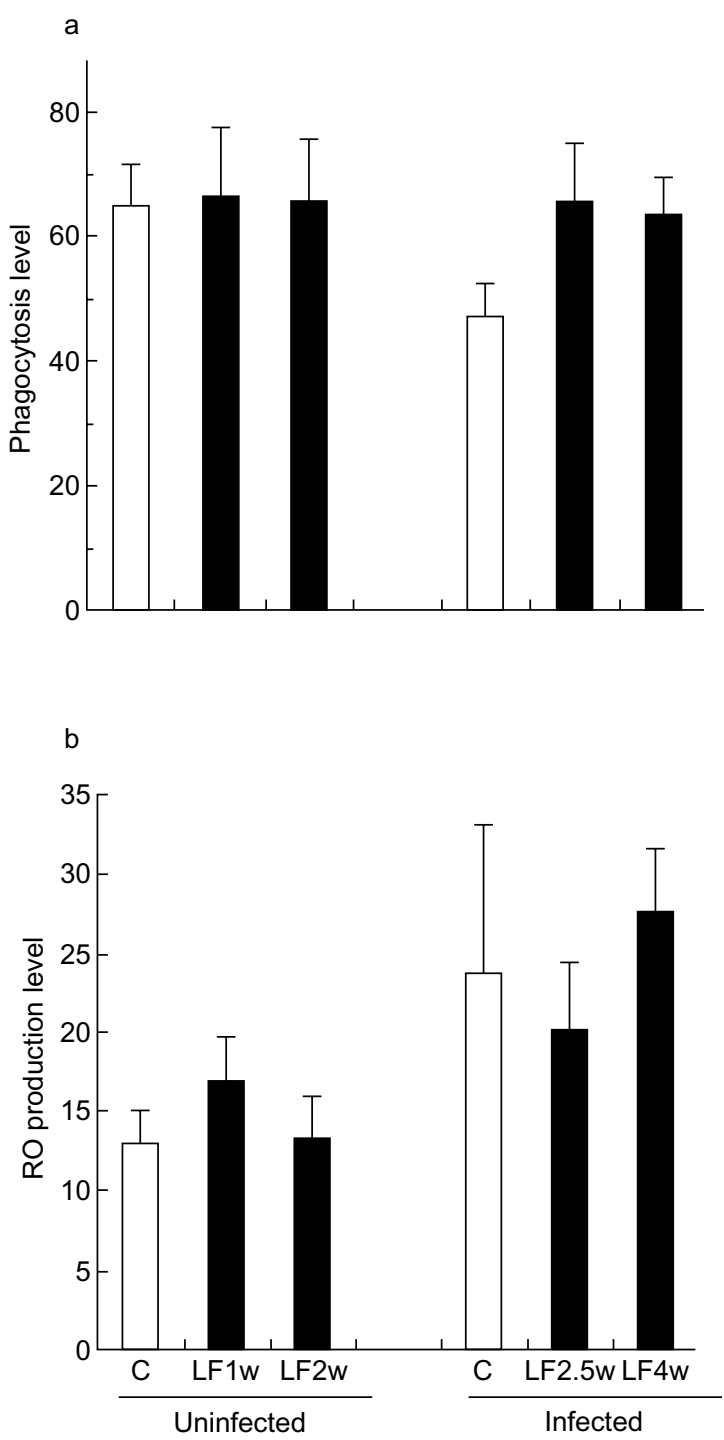

Fig. 2. Phagocytic activity and RO production of neutrophils. Normal guinea-pigs were given water for 2 weeks or LF for 1 or 2 weeks. T. mentagrophytes-infected guinea-pigs were given nothing or LF for 2.5 or 4 weeks. One day after the administration period, phagocytic activity (a) and PMA-stimulated RO production (b) of neutrophil PMNLs were estimated by flow cytometry. Data represent mean and SEM $(n=5-7)$.

animals appeared to be higher in immunised animals than in non-immunised animals.

\section{Effect of MNC culture supernate on T. mentagrophytes-killing activity of macrophages}

The effector activity of MNC for modulation of the $T$. mentagrophytes-killing activity of macrophages was examined in guinea-pigs that had been immunised or were non-immunised. One week after immunisation of the guinea-pigs, the MNC were isolated and cultured with stimulation by ConA or heat-killed T. mentagrophytes cells, and the culture supernate was then collected and added to the T. mentagrophytes-killing assay system at $10 \%$ concentration. The resident peritoneal macrophages alone killed $26 \%$ of $T$. mentagrophytes conidia (Fig. 4). The killing activity 


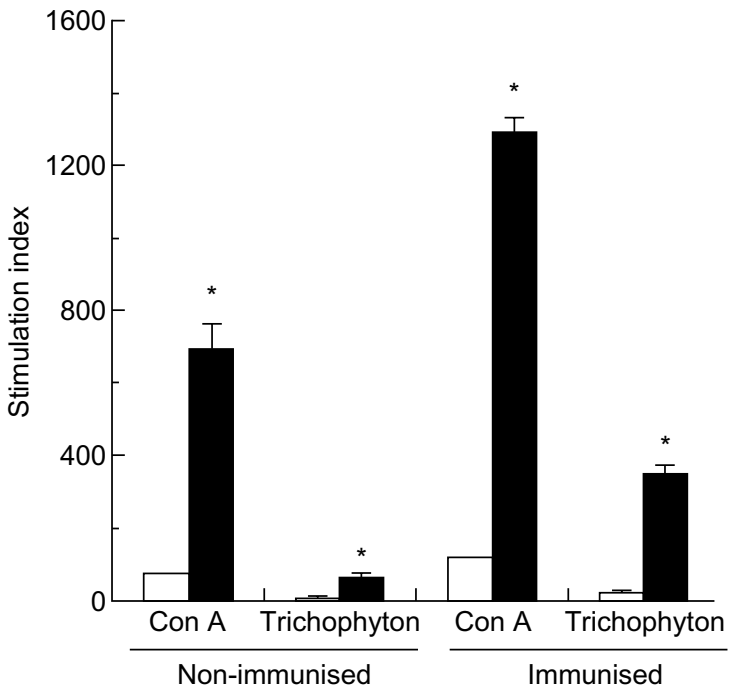

Fig. 3. Proliferative response of MNC. Non-immunised guinea-pigs and guinea-pigs immunised with inactivated T. mentagrophytes were given nothing or LF for 7 days. One day after the administration period, splenic MNC were incubated with ConA or inactivated T. mentagrophytes for 3 days and BrdU incorporation was assayed in triplicate. Data represent mean and SEM $(n=3)$ of the stimulation index relative to basal BrdU incorporation for the control ( $\square$ ) and LF-treatment (ם) groups. ${ }^{*} \mathrm{p}<0.05$ versus control by two-tailed $t$ test.

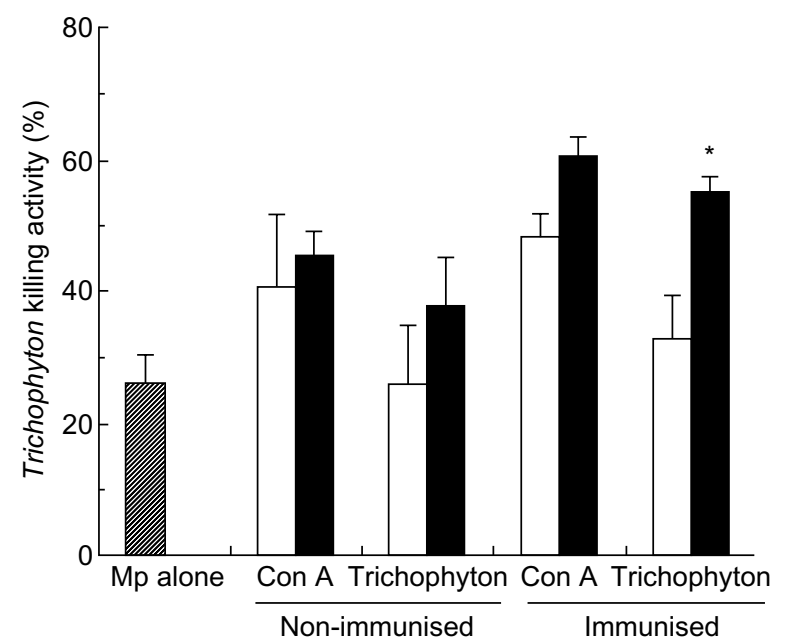

Fig. 4. Effect of MNC supernate on the T. mentagrophyteskilling activity of macrophages. Non-immunised guinea-pigs and guinea-pigs immunised with inactivated T. mentagrophytes were given nothing or LF for 7 days. One day after the administration period, splenic MNC were incubated with ConA or inactivated T. mentagrophytes for 2 days and the culture supernate was collected. The supernate was added at $10 \%$ concentration to naive peritoneal macrophage cultures, and the T. mentagrophytes-killing activity of the macrophages $(\mathrm{E} / \mathrm{T}$ ratio $=5 / 1)$ was determined in triplicate. Data represent mean and SEM $(\mathrm{n}=3)$ of $T$. mentagrophytes-killing activity for macrophages alone, macrophages with supernates from the control ( $\square$ ) and LF-treatment (ם) groups. ${ }^{*} \mathrm{p}<0.05$ versus control by two-tailed $t$ test.

of the macrophages was increased to $60 \%$ as a result of the addition of the MNC supernate. Comparison of control and LF-treated animals showed that T. mentagrophytes-killing appeared to be higher when macro- phages were treated with MNC supernate derived from LF-treated animals and the enhancement by LFtreatment was significant in the case of supernate from T. mentagrophytes-stimulated MNC of immunised animals.

Supernate was collected from T. mentagrophytesstimulated MNC of immunised and LF-administered animals. The effect of the supernate on the $T$. mentagrophytes-killing of macrophages was observed dose-dependently over the concentration range of 2$20 \%$ (Fig. 5). However, the supernate alone without macrophages did not show any killing activity. Similarly, recombinant rat IFN- $\gamma$ enhanced the $T$. mentagrophytes-killing activity of guinea-pig macrophages at the relatively high concentration of $1 \mu \mathrm{g} / \mathrm{ml}$ (3200 U/ml) (Fig. 6).

\section{Discussion}

This study investigated the effects of oral administration of LF on the host antifungal response in guineapigs infected or immunised with T. mentagrophytes. The plasma UIBC value was correlated with the effect on growth of T. mentagrophytes. This indicates that the iron-binding capacity of plasma, which is considered to reflect the transferrin content, plays a role in limiting growth of $T$. mentagrophytes, as demonstrated previously $[10,11]$. The UIBC of infected animals seemed to be somewhat higher than that of uninfected animals. The infection or the state of inflammation may have influenced the plasma UIBC value. However, LF

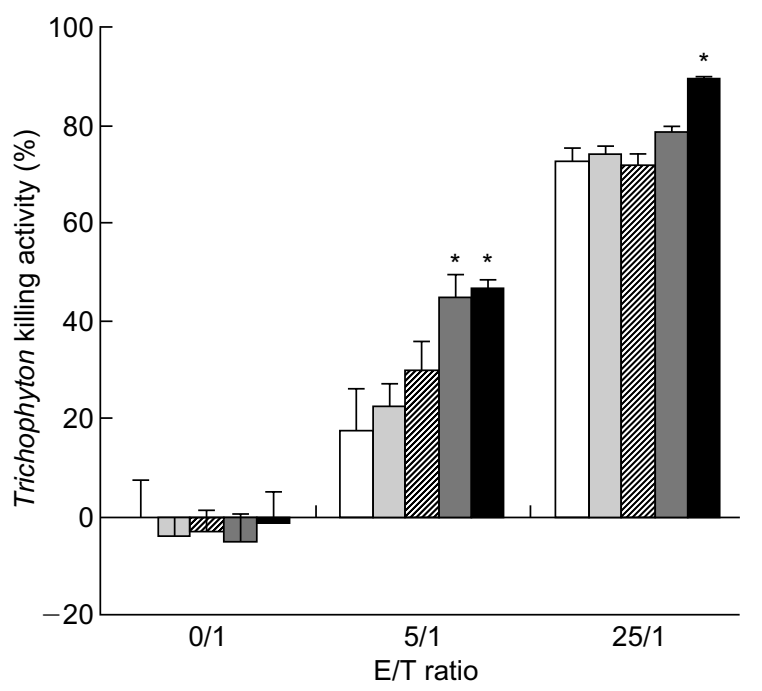

Fig. 5. Dose-response of MNC supernate on the T. mentagrophytes-killing activity of macrophages. Guinea-pigs were immunised and given LF, and supernate was collected from MNC isolated from these guinea-pigs and cultured with inactivated T. mentagrophytes. Various concentrations of the supernate $(0$, $2,5,10,20 \%$; left to right columns) were assayed for $T$. mentagrophytes-killing activity without macrophages $(\mathrm{E} / \mathrm{T}=0 / 1)$ or with macrophages $(\mathrm{E} / \mathrm{T}=5 / 1$ or $25 / 1)$ in triplicate. Data represent mean and SEM $(n=3) .{ }^{*} \mathrm{p}<0.05$ versus $0 \%$ of the supernate by two-tailed $t$ test. 


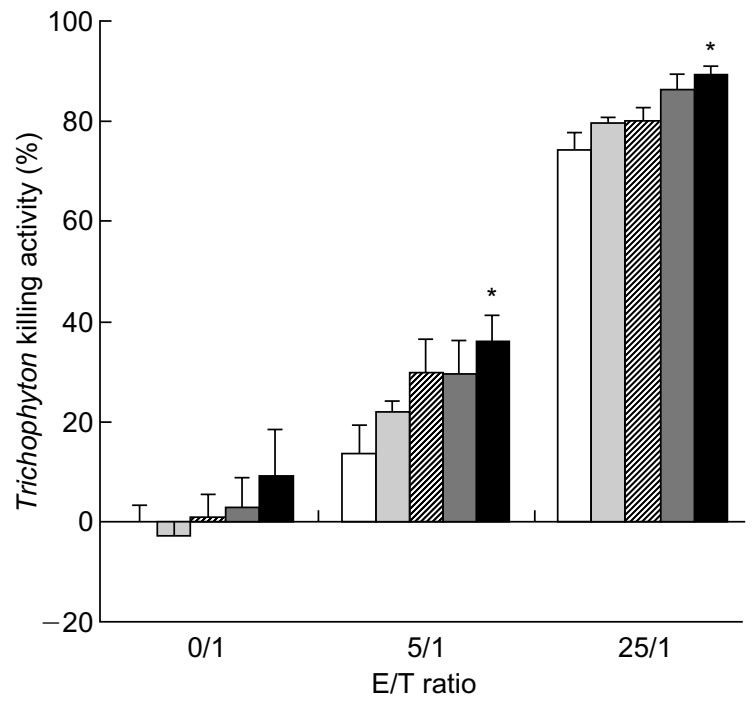

Fig. 6. Effect of recombinant rat IFN- $\gamma$ on the T. mentagrophytes-killing activity of macrophages. Various concentrations of IFN- $\gamma(0,1,10,100,1000 \mathrm{ng} / \mathrm{ml}$; left to right columns) were assayed for T. mentagrophytes-killing activity without macrophages $(E / T=0 / 1)$ or with macrophages $(E / T=5 / 1$ or 25/1) in triplicate. Data represent mean and SEM $(\mathrm{n}=3)$. ${ }^{*} \mathrm{p}<0.05$ versus $0 \mathrm{ng} / \mathrm{ml}$ of IFN- $\gamma$ by two-tailed $t$ test.

administration did not enhance UIBC or the anti- $T$. mentagrophytes activity of the plasma in uninfected or infected animals. Indeed, plasma from two LF-treated, infected animals showed the lowest UIBC and promoted growth of $T$. mentagrophytes. This may have been due to accelerated resolution of the infection in the LF-administered animals [8]. In fact, these two animals showed a low fungal burden of the skin (score of 1 , data not shown).

LF administration did not significantly alter the blood neutrophil PMNL activities in uninfected or infected animals, although it augmented to some extent the phagocytic activity in infected animals. It is known that LF or its peptide fragment(s) stimulate phagocytic activity [23] and superoxide production [24] of neutrophil PMNLs in vitro. Recently, it was reported that intravenous injection of LF peptide upregulates neutrophil PMNL functions, including superoxide generation, in Candida albicans-infected mice [25]. Such effects of LF may not be exerted by orally administered LF, because substantial amounts of LF or LF fragments cannot be absorbed from the intestinal lumen, as shown previously [26].

In guinea-pigs immunised with heat-killed T. mentagrophytes cells, the study examined the functions of splenic MNC. First, enhancement of the proliferative response of $\mathrm{MNC}$ upon stimulation with ConA or inactivated $T$. mentagrophytes was observed as a result of LF administration. Second, an in-vitro system was constructed for measuring T. mentagrophytes-killing by macrophages and the modulating activity of MNC supernate was tested in this system. When guinea-pigs were immunised and the MNC collected from these guinea-pigs were stimulated with inactivated $T$. mentagrophytes, the culture supernates of MNC derived from LF-administered animals induced significantly higher $T$. mentagrophytes-killing by macrophages than supernates from animals not given LF. These results indicate that, upon ingestion, LF acts as a second signal that augments the function of MNC when animals have received foreign antigens. Augmentation of cellmediated immunity by oral administration of LF is suggested by the present results and previous findings. A previous study in guinea-pig models of dermatophytosis found that LF feeding did not prevent inflammation related to cell-mediated immunity but promoted the clinical curing of skin lesions after the development of symptoms [8]. Another group showed that oral administration of LF at the time of immunisation with several antigens increased the DTH responses [27]. Facilitated elimination of fungi by LF administration in the dermatophytosis models [8] may be mediated at least partly by enhanced cell-mediated immunity.

It has been reported that the ability of ConA-stimulated murine splenic cell supernate to induce antimicrobial effects of macrophages is attributable to IFN- $\gamma$ [28]. Although it is known that guinea-pigs produce IFNs [29], the identification of guinea-pig IFN- $\gamma$ has not been reported yet. Accordingly, the present study could not identify an active component released from MNC as IFN- $\gamma$. Instead, it showed that a relatively high concentration of recombinant rat IFN- $\gamma$ augmented the T. mentagrophytes-killing activity of guinea-pig macrophages. A previous report indicated that IFN- $\gamma$ production by $\mathrm{CD}^{+}$splenocytes in mice is increased by oral administration of LF [30]. LF feeding also increased the number of IFN- $\gamma^{+}$cells in the small intestinal mucosa of mice [31]. These findings suggest the possibility that the macrophage-activating component released from the guinea-pig $\mathrm{MNC}$ is an IFN- $\gamma$ like cytokine.

This study could not detect any obvious activation of peripheral blood neutrophils by LF feeding. Phagocytic cells, including neutrophil PMNLs and macrophages, may be activated at the infected locus with the help of MNC. Further investigations are under way to clarify the immunological and molecular events induced by the oral administration of LF.

\section{References}

1. Brock J. Lactoferrin: a multifunctional immunoregulatory protein? Immunol Today 1995; 16: 417-419.

2. Weinberg ED. Human lactoferrin: a novel therapeutic with broad spectrum potential. J Pharm Pharmacol 2001; 53: 1303-1310.

3. Bhimani RS, Vendrov Y, Furmanski P. Influence of lactoferrin feeding and injection against systemic staphylococcal infections in mice. J Appl Microbiol 1999; 86: 135-144.

4. Håversen LA, Engberg I, Baltzer L, Dolphin G, Hanson LÅ, Mattsby-Baltzer I. Human lactoferrin and peptides derived from a surface-exposed helical region reduce experimental 
Escherichia coli urinary tract infection in mice. Infect Immun 2000; 68: 5816-5823.

5. Abe $\mathrm{S}$, Okutomi $\mathrm{T}$, Tansho $\mathrm{S}$ et al. Augmentation by lactoferrin of host defense against Candida infection in mice. In: Shimazaki K, Tsuda H, Tomita M, Kuwata T, Perraudin J-P (eds) Lactoferrin: structure, function and applications. International Congress Series no. 1195. Amsterdam, Elsevier Science BV. 2000: 195-201.

6. Isamida T, Tanaka T, Omata Y, Yamauchi K, Shimazaki K, Saito A. Protective effects of lactoferricin against Toxoplasma gondii infection in mice. J Vet Med Sci 1998; 60: 241-244.

7. Tanaka K, Ikeda M, Nozaki A et al. Lactoferrin inhibits hepatitis $\mathrm{C}$ virus viremia in patients with chronic hepatitis $\mathrm{C}$ : a pilot study. Jpn J Cancer Res 1999; 90: 367-371.

8. Wakabayashi $\mathrm{H}$, Uchida $\mathrm{K}$, Yamauchi $\mathrm{K}$, Teraguchi $\mathrm{S}$, Hayasawa $H$, Yamaguchi $H$. Lactoferrin given in food facilitates dermatophytosis cure in guinea pig models. $J$ Antimicrob Chemother 2000; 46: 595-601.

9. Yamauchi K, Hiruma M, Yamazaki N et al. Oral administration of bovine lactoferrin for treatment of tinea pedis. A placebocontrolled, double-blind study. Mycoses 2000; 43: 197-202.

10. King RD, Khan HA, Foye JC, Greenberg JH, Jones HE. Transferrin, iron, and dermatophytes. I. Serum dermatophyte inhibitory component definitively identified as unsaturated transferrin. J Lab Clin Med 1975; 86: 204-212.

11. Artis WM, Patrusky E, Rastinejad F, Duncan RL. Fungistatic mechanism of human transferrin for Rhizopus oryzae and Trichophyton mentagrophytes: alternative to simple iron deprivation. Infect Immun 1983; 41: 1269-1278.

12. Roberts SOB, Mackenzie DWR. Mycology. In: Rook A, Wilkinson DS, Ebling FJG (eds) Textbook of dermatology, 3rd edn, vol 1. Oxford, Blackwell Scientific. 1979: 767-868.

13. Hay RJ, Calderon RA, Collins MJ. Experimental dermatophytosis: the clinical and histopathologic features of a mouse model using Trichophyton quinckeanum (mouse favus). J Invest Dermatol 1983; 81: 270-274.

14. Calderon RA, Hay RJ. Fungicidal activity of human neutrophils and monocytes on dermatophyte fungi, Trichophyton quinckeanum and Trichophyton rubrum. Immunology 1987; 61: 289-295.

15. Weitzman I, Summerbell RC. The dermatophytes. Clin Microbiol Rev 1995; 8: 240-259.

16. Jones HE. Immune response and host resistance of humans to dermatophyte infection. J Am Acad Dermatol 1993; 28 S12-S18.

17. Koga $\mathrm{T}$, Ishizaki $\mathrm{H}$, Matsumoto $\mathrm{T}$, Hori $\mathrm{Y}$. In vitro release of interferon- $\gamma$ by peripheral blood mononuclear cells of patients with dermatophytosis in response to stimulation with trichophytin. Br J Dermatol 1993; 128: 703-704.

18. Koga T, Ishizaki H, Matsumoto T, Hori Y. Cytokine production of peripheral blood mononuclear cells in a dermatophytosis patient in response to stimulation with trichophytin. $J$ Dermatol 1993; 20: 441-443.
19. Koga $\mathrm{T}$, Ishizaki $\mathrm{H}$, Matsumoto $\mathrm{T}$, Hori $\mathrm{Y}$. In vitro release of granulocyte/macrophage colony-stimulating factor by peripheral blood mononuclear cells of dermatophytosis patients in response to stimulation with trichophytin. Clin Exp Dermatol 1994; 19: 94-95.

20. Koga T, Ishizaki H, Matsumoto T, Hori Y. Decreased release of interferon- $\gamma$ by peripheral blood mononuclear cells of patients with chronic dermatophytosis in response to stimulation with trichophytin. Acta Derm Venereol 1995; 75: 81-82.

21. Kruisbeek AM. Isolation of mouse mononuclear cells. In: Coligan E, Kruisbeek AM, Margulies DH, Shevach EM, Strober W (eds) Current protocols in immunology. New York, John Wiley \& Sons. 1993: 3.1.2-3.1.5.

22. National Committee for Clinical Laboratory Standards. Reference method for broth dilution antifungal susceptibility testing of conidium-forming filamentous fungi, proposed standard M38-P. Wayne, NCCLS. 1998.

23. Miyauchi H, Hashimoto S, Nakajima M, Shinoda I, Fukuwatari Y, Hayasawa H. Bovine lactoferrin stimulates the phagocytic activity of human neutrophils: identification of its active domain. Cell Immunol 1998; 187: 34-37.

24. Gahr M, Speer CP, Damerau B, Sawatzki G. Influence of lactoferrin on the function of human polymorphonuclear leukocytes and monocytes. J Leukoc Biol 1991; 49: 427-433.

25. Tanida T, Rao F, Hamada T, Ueta E, Osaki T. Lactoferrin peptide increases the survival of Candida albicans-inoculated mice by upregulating neutrophil and macrophage functions, especially in combination with amphotericin B and granulocyte-macrophage colony-stimulating factor. Infect Immun 2001; 69: $3883-3890$.

26. Kuwata H, Yamauchi $\mathrm{K}$, Teraguchi $\mathrm{S}$ et al. Functional fragments of ingested lactoferrin are resistant to proteolytic degradation in the gastrointestinal tract of adult rats. $J$ Nutr 2001; 131: 2121-2127.

27. Zimecki M, Kruzel ML. Systemic or local co-administration of lactoferrin with sensitizing dose of antigen enhances delayed type hypersensitivity in mice. Immunol Lett 2000; 74: $183-188$.

28. Fortier AH, Polsinelli T, Green SJ, Nacy CA. Activation of macrophages for destruction of Francisella tularensis: identification of cytokines, effector cells, and effector molecules. Infect Immun 1992; 60: 817-825.

29. Dejean CB, Ayerra BL, Teyssie AR. Interferon response in the guinea pig infected with Junin virus. J Med Virol 1987; 23: $83-91$.

30. Nakajima M, Iwamoto $H$, Shirasawa $\mathrm{T}$ et al. Oral administration of lactoferrin enhances the productions of IFN- $\gamma$ and IL-10 in spleen cells cultured with concanavalin A or lipopolysaccharide. Biomed Res 1999; 20: 27-34.

31. Wang W-P, Iigo M, Sato J, Sekine K, Adachi I, Tsuda H. Activation of intestinal mucosal immunity in tumorbearing mice by lactoferrin. Jpn J Cancer Res 2000; 91: $1022-1027$. 